\title{
The Discussion of Traditional Teaching and Multimedia Teaching Approach in College English Teaching
}

\author{
Chunyang Liu, Fei Long \\ Department of Foreign Language, Harbin University of Commerce Harbin, Hei Longjiang Province, China \\ tracyliu0303@sina.com, longlongruby@126.com
}

\begin{abstract}
With the development of the society and economy, more and more talents capable of mastering English are badly needed in the world. Therefore, traditional English teaching mode is greatly challenged. With the continuous development of modern technology, multimedia is applied to teaching more and more widely. This is of special significance to English teaching. Then, how to use multimedia effectively? This paper analyses the advantages and disadvantages of multimedia teaching and traditional teaching on the base of English teaching in universities, and discusses how to combine multimedia teaching together with traditional teaching according to the teaching practice of universities. It is an effective way to combine multimedia with the traditional teaching approach, though it needs a long time to combine them perfectly.
\end{abstract}

Index Terms - English teaching in university; multimedia teaching; traditional teaching

\section{Introduction}

With the development of modern technology, multimedia has been applied to teaching widely, however, as for English teaching, the traditional way has been shocked, multimedia teaching has been applied to English teaching class gradually, which reformed the teaching method, concept and form of teaching materials, class structure, ideology and theory. An impeccable and mature multimedia network English teaching system is being formed among many colleges, which adds vitality to the reformation of college English class and makes various image teaching method, breaking the traditional mode and broadening the horizon of students, also, it improves the efficiency on the class. We should comprehend and understand the advantage and disadvantage between multimedia teaching and traditional teaching, combining which to achieve the efficient and high-quality effect.

\section{The Advantage and Disadvantage of Multimedia Teaching}

\section{A. The advantage of multimedia teaching}

The multimedia teaching is a design that selects and applies teaching media reasonably, according to the characteristics of teaching target and aim, organically combining with traditional teaching method to participate the whole teaching process, simultaneously, forming reasonable teaching process and structure to achieve the optimized teaching. Utilize multimedia networking to improve class efficiency, increase the active involvement of the students and cultivate their ability of using English comprehensively technology for language training through exploring, interaction, cooperation etc. .

Multimedia teaching breaks the traditional teacher-centered way, which shifts the focus to the students, who could obtain the knowledge under guidance of teacher via the interaction between them. During the period of English learning, if all the senses can be triggered together, then enthusiasm of students is mobilized furthest. The networking method creates English communication scenario, which visualizes the abstract and unfamiliar knowledge, from which students can learn language knowledge and cultural background information in more characteristic language environment. With the help of network transmission technology, virtual space, communication media and electronic dictionary etc. multimedia offers intuitive interface vividly. The students join learning activities delightfully, therefore, their motive and interest is stimulated. It is the most outstanding modern teaching media that owns the incomparable control and man-machine conversation.

The modern teaching reflects the themes of our era, with its abundant information. Multimedia assists English teaching, displaying contents actively and intuitively, which makes them talk and communicate the relative concrete content joyfully, also, students obtain perceptual understanding from so vivid and large information, generating distinct image and inspiring their thinking so that to deepen their understanding of learning content within a short time. Multimedia realizes openness, interaction, sharing, cooperation and autonomy of English learning between teaching and learning, which renders all-round sensory stimulation. Cognitive psychology argues that mobilizing multiple senses to apperceive is more comprehensive, profound than the single one[2]. Simultaneously, it improves input of information overtly and quickens the tempo on the class, also, increases the efficiency [7]. Network makes the students' learning scope beyond teaching materials, which guides college English learning to a direction of individuation and independency, not rigidly adhere to time and space.

\section{B. The disadvantages of multimedia teaching}

It is no doubt that the advantage of network teaching is obvious, however, there still exists misunderstandings for some teachers because of their lack of theory guidance.

Teachers should spend much time on courseware using multimedia teaching from the degree of teaching effectiveness. They focus their attention just on the multimedia but on the state of the learners, supposing the multimedia teaching is modern teaching unilaterally, which leads to low efficiency of learning, which constrains their positivity and is adverse to the creation and development of their thoughts. The rampant e-books are harmful for students' eyes from healthy percept, 
meanwhile, without the teacher's guidance, the learners are likely to be addicted to it due to the abundance of network information and games, which affect their learning effect. To improve learning interest, the teachers redundantly add music video and other cartoons, whose content is not available, but not to actualize the teaching according to their requirements. Though the climate turns to be active, the teaching points is not given top priority.

\section{The Advantage and Disadvantage of Traditional Teaching}

\section{A. The advantage of traditional teaching}

The traditional teacher-centered mode is propitious to come into play as a guider, the teacher supervise the whole teaching activity, imparting systemic knowledge and academic opinions with speculative philosophy, abundant emotional thoughts and unique manner which effect students potentially, from which they receive wisdom and power that is good for the development of their IQ and EQ. At the same time, with the special training of normal university, they understand the education regulation and hold experience of teaching content and method. Teachers can change them in accordance of their aptitude for a better explanation. What's more, face to face communication is a stimulative factor for students' comprehensive quality.

The traditional teaching is the most direct and effective method. Teachers control and inspire students effectively when the students encounter problems or arise conflicts, they take flexible teaching method adjusting the content according to actual requirement under the general teaching arrangement, which is not only conductive to cultivate the basic technique but also for the good habit in forming students' self-study ability. Teachers' action and language become the target imitated by learners, whose outlook towards right and wrong, attitude, value orientation and academic level have great impact on students.

\section{B. Problems of traditional English teaching}

As professor Bruner (1982) of Harvard University points out: "the teaching process is a continuous activity of asking questions and solving them." [1] Traditional college English teaching puts teachers as the center all the time, mainly relying on class knowledge, which emphasizes the role of teachers too much. It curbs personality and creativity of students and ignores the initiative and potential of the students, therefore, students are in a passive position. This traditional teaching method mainly has the following disadvantages:

Teaching mode is single. In the teaching process the teacher is the center, and the teaching process emphasizes system and completion but few thinking space for students. Students are passive in the class teaching and teachers cannot take care of every student in class who has different basis and interests. Students are listeners and put the teacher as the center. The knowledge is limited; the resource is scarce; the learning is passive but the knowledge is well-formed and departed from real life. The main experience is insufficient or lack of subjective experience, which will restrict the effectiveness of learning strategy teaching. Many students lose interest in English because their initiative and enthusiasm cannot be fully exerted in class.

\section{Combination of the Modernized Teaching Method and Traditional Teaching Method}

It's an important developing trend to use multimedia technology and internet in English teaching class. The two teaching methods are complemented with each other. The traditional teaching method focuses on the rational knowledge of the language-rules and frame. The modern teaching method use the multimedia technology as the assistant method focuses on the practical application and specific operations of the language. We'd better not only promote the advantages of the traditional teaching method but also use the multimedia rationally to achieve the best teaching results. Timely adequate and appropriate are the rules of multimedia teaching, we should lead the students to use the advanced technology to find out the information and material out of the books to increase the stock of knowledge, expand and consolidate learning content. By this way we can get a new teaching style that combine the advantages of the traditional methods and modern methods. Innovate teaching ideas and methods; combine the advanced teaching methods with scientific teaching methods. Combining the advantages of the two teaching methods could achieve the best teaching results, improve the English language skills of the students' and improve the quality of teaching. As the Professor Xuan Weibo and Yu Yelu argues: compared with only use one media, use more than one media is better, using different properly medias and methods could not only improve the students' interests but also enriched the subjects [6].

\section{Conclusion}

In conclusion, in the process of English teaching informationalized development, "Foresee is necessary, to decide how to combine internet with teaching successfully in advance." [8]. Introducing multimedia assistant teaching into college English, teachers should not only apply multimedia technology to direct students, but also concern their interest and teaching objectives, only in this way, the best teaching effect is obtained. Undoubtedly, it is a reformational trend that integration is inexorable between internet technology and English subject. To keep learning and promoting, to accept new teaching theory, to improve ability and level of new technology is essential to every teacher. Researching and exploring the new methods of multimedia teaching has become an inevitable trend for college English teaching.

\section{References}

[1] Bruner, The process of education, Culture and Education Press, 1982.

[2] Chen Shu, The Relations between Culture and Foreign Language Teaching, Ghostwritten Paper Foreign Language Teaching, 1998, (2):1-4.

[3] He Gaoda, Zhou Jianxia, Listening and Speaking in Advanced Normal University of English Major, Computer-assisted Foreign Language Education, 1996(4):728.

[4] Robert Makin, Emotional Management--a high EQ Executive, Guangzhou: Zhongshan University Press, 1999.

[5] Wang Haizhen, Su Xiaojin, Multimedia and College English Teaching[, 
Computer-assisted Foreign Language Education, 1994.

[6] Xuan Weibo, Yu Yelu, Understanding Human Communication: Men, Women, Messages and Media Beijing: Outlook in China Press, 1985.

[7] Yang Yang, The Research on Multimedia Assist Teaching in Junior School, Computer-assisted Foreign Language Education2001, (3):50-51.
[8] Zhu Zhiting, Informationalized Education and Education Reformation-Computer and Education, Xinan Normal University Press, 1991 